\title{
CHANGES IN LEVEL OF C-REACTIVE PROTEIN AT 0 HOURS AND AT 72 HOURS AMONG NEONATES WITH SUSPECTED SEPSIS AT NEONATAL INTENSIVE CARE UNIT OF BIRAT MEDICAL COLLEGE TEACHING HOSPITAL
}

\author{
Ramesh Yadav ${ }^{1^{*}}$, Hem Sagar Rimal ${ }^{2}$, Santosh Upadhyaya Kafle ${ }^{3}$
}

\section{Affiliation}

1. Lecturer, Department of Paediatrics, Birat Medical College Teaching Hospital

2. Professor \& Head of Department of Paediatrics, Birat Medical College Teaching Hospital

3. Professor \& Head of Department of Pathology, Birat Medical College Teaching Hospital

\section{ARTICLE INFO}

Received : 18 October, 2021

Accepted : 05 January, 2021

Published : 21 February, 2022

(C) Authors retain copyright and grant the journal right of first publication with the work simultaneously licensed under Creative Commons Attribution License CC - BY 4.0 that allows others to share the work with an acknowledgment of the work's authorship and initial publication in this journal.

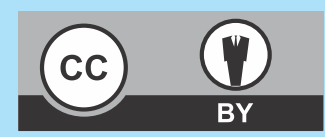

ORA 283

DOI: https://doi.org/10.3126/bjhs.v6i3.43213

* Corresponding Author

Dr. Ramesh Yadav

Lecturer

Département of Paediatrics

Birat Medical College Teaching Hospital, Nepal

Email: imramesh4u1315@gmail.com

ORCID: https://orcid.org/0000-0002-8672-5314

\section{Citation}

Changes in Level of C-Reactive Protein at 0 Hours and at 72 Hours among Neonates with Suspected Sepsis at Neonatal Intensive Care Unit of Birat Medical College Teaching Hospital. Ramesh Yadav, Hem Sagar Rimal, Santosh Upadhyaya Kafle. BJHS 2021;6(3)16. 1636-1641.

\section{ABSTRACT}

\section{Introduction}

Neonatal sepsis still remains serious and potentially lifethreatening events with a mortality rate of up to $50 \%$ in very premature infants. Efforts were made to improve laboratory sepsis diagnosis. C-reactive protein (CRP) is the most extensively studied acute phase reactant so far. Very few studies have been done to see the variation of serial measurement of CRP titer.

\section{Objectives}

To find out the level of CRP titer at 0 hour and at 72 hours among neonates with suspected sepsis at the neonatal intensive care unit of Birat Medical College Teaching Hospital.

\section{Methodology}

It was a cross-sectional descriptive study from 26 March 2021 to 25 July 2021, to see serial CRP titre among the sepsis suspected neonates at the Neonatal intensive care unit of Birat Medical College Teaching Hospital. A Total of 95 cases of neonates suspected sepsis were enrolled and their serial CRP titre at 0 hour and 72 hours were studied. The data was entered into Microsoft office excel and analyzed using statistical package for social sciences (SPSS 20.0)

\section{Results}

There was no significant association of gender, birth weight, mode of delivery and gestational age with an increase of CRP at 0 to 72 hours after birth. Among the enrolled neonates 34 had positive blood culture while 61 had blood culture which was sterile. It showed that, $70.6 \%$ who had blood culture positive had increased CRP level at 0 to 72 hours whereas only $29.4 \%$ had not no increment in CRP despite positive blood culture.

\section{Conclusions}

CRP titre increment at 72 hours after the first one correlated better with culture proven sepsis in comparison to CRP titer increment at 0 hours after birth. The sensitivity, specificity, positive and negative predictive values as calculated in this study are not high enough to make it a good screening test. The test is not specific enough to rely upon as the sole indicator. The clinical judgment along with other hematological parameters and diagnostic markers along with serial CRP should be considered in evaluating a neonate for sepsis.

\section{KEYWORDS}

C-reactive protein, Neonatal sepsis 


\section{INTRODUCTION}

During the last decades advances in neonatal intensive care have led to an impressive decrease of neonatal mortality and morbidity. However, infectious episodes in the early postnatal period still remain serious and potentially lifethreatening events with a mortality rate of up to $50 \%$ in very premature infants. ${ }^{1}$ The signs and symptoms of neonatal sepsis is clinically indistinguishable from various noninfectious conditions such as respiratory distress or maladaptation. Therefore, rapid diagnosis is crucial for preventing the child from an adverse outcome. The current practice of starting empirical antibiotic therapy in all neonates showing infection-like symptoms results in their exposure to adverse drug effects, nosocomial complications, and in the emergence of resistant strains. ${ }^{2}$

Laboratory sepsis markers represent a helpful tool in the evaluation of a child with clinical signs and complement the evaluation of a neonate with a potential infection. The tests used include the white blood cell count (WBC) and assays for markers of inflammatory reaction in serum, such as, Creactive protein (CRP), interleukin-6 (IL-6), tumor necrosis factor alpha (TNF- $\alpha$ ) and procalcitonin. During the last decades efforts were made to improve laboratory sepsis diagnosis and a variety of the markers and more were studied with different success. Despite the promising results for some of them, current evidence suggests that none of them can consistently diagnose $100 \%$ of infected cases. C-reactive protein (CRP) is the most extensively studied acute phase reactant so far and despite the ongoing rise (and fall) of new infection markers it still remains the preferred index in many neonatal intensive care units. ${ }^{3}$

Suspected neonatal sepsis were considered if neonate had features of perinatal risk factors i.e., maternal pyrexia (within 1 week prenatal and/or 48 hours postnatal), prolonged rupture of membranes (18 hours), foul smelling vaginal discharge or/and maternal urinary tract infection diagnosed in last month. Neonates having unexplained hypothermia/hyperthermia, lethargy, irritability, poor feeding or milk intolerance, tachypnoea (>60 breaths/ minute), cardiovascular dysfunction such as persistent tachycardia (>160 beat/min) or bradycardia (<100beats/min), poor peripheral circulation, hypotonia or circumoral cyanosis or pallor, birth asphyxiated neonates, low birth weight $<2500$, very low birth weight $<1500$ grams and extremely premature $<32$ weeks gestation. A newborn will suffer if infection is not diagnosed properly: under diagnosed or over diagnosed. For early diagnosis of newborn sepsis, combined and/or alone interleukin-6 (IL-6) and C-reactive protein (CRP), has a recognized role. CRP production is a non-specific response to disease and cannot be used alone as a diagnostic test for septicemia. Along with clinical evidence of the disease, CRP provides good ideas regarding septicemia diagnosis. In many centers only one CRP test is done on admission and if it comes out to be negative, antibiotics are stopped and later on the baby comes back with severe sepsis. CRP serial measurement in infection progress is helpful, also in infection diagnosis. Very few studies have been done to see the variation of serial measurement of CRP titre with blood culture. Checking the variation of quantitative CRP titre when done twice, one at admission and second at 72 hours after the first one with blood culture seems essential. ${ }^{4}$

Hence, we aimed to find out the level of CRP titre and how it varies according to gestational age, gender, birth weight, types of sepsis, modes of delivery, different laboratory parameters at 0 to 72 hours among sepsis suspected neonates in the Neonatal intensive care unit of Birat Medical College Teaching Hospital. We also aimed to assess the differences in level of CRP titre among sepsis suspected neonates at admission and after 72 hours with blood culture proven sepsis.

\section{METHODOLOGY}

It was a cross-sectional descriptive study from 26 March 2021 to 25 July 2021, to see variation in CRP titer with blood culture among the neonates suspected of sepsis at the Neonatal intensive care unit of Birat Medical College Teaching Hospital. A total 95 sample sizes were calculated by using expected prevalence $62 \%$, desired precision $10 \%$ and confidence level 95\%. After taking informed and written consent from parents and approval from the institutional review committee, neonates brought to the neonatal intensive care unit of BMCTH were selected by non-probability consecutive sampling techniques. Neonates suspected of sepsis and planned to treat with injectable antibiotics by the treating pediatrician were included. Neonates who already had taken antibiotics prior to admission and parents unwilling to give written consent were excluded. All patients included were started on empirical antibiotics after drawing samples for blood cultures and CRP along with other investigations advised by the treating physician and sent to the laboratory. Strict aseptic measures were taken while taking blood for investigations. For CRP blood was collected in plain vial without any anticoagulants and the tests were performed by Huma Tex CRP latex agglutination slide test. A second sample for determination of CRP was drawn 72 hours after the first one. For blood culture $1 \mathrm{ml}$ of blood were drawn. Blood culture bottles were checked for expiry date printed on each bottle. $1 \mathrm{ml}$ each of blood was inoculated in a blood culture bottle containing media i.e., Blood Agar or MacConkey Agar media. Blood culture bottles were clearly labeled with the name of the patient and date and time of collection of blood before sending to the laboratory. Blood culture and sensitivity were performed by BD BACTEC.

If the first CRP titre was non-significant, the antibiotic therapy was continued and if the second CRP was also nonsignificant, the decision to continue or discontinue antibiotic was decided by the treating physician. But, if there was significant rise in the second CRP titre, the antibiotics were continued or changed, looking at the clinical status of the patient and decided by the treating physician. If first and second CRP both were positive, the therapy was continued and the culture and sensitivity report were awaited. CRP was read as negative when level was $<6 \mathrm{mg} / \mathrm{dl}$ and positive when level $>$ or $=6 \mathrm{mg} / \mathrm{dl}$ and titer were recorded. Blood culture was followed for growth up to 7 days. 
Data collection was done using a specifically designed questionnaire. All the data were entered in excel sheets and converted into SPSS version 20. The descriptive and inferential statistics were used for data analysis. The test of significance was done by the chi-square test. The sensitivity, specificity, negative predictive value and positive predictive value of CRP to diagnose neonatal sepsis at 0 hours and at 72 hours were calculated separately taking blood culture as standard. Sensitivity was calculated dividing true positive by summation of true positive and false negative. Specificity was calculated dividing true negative by summation of false positive and true negative. Positive predictive value calculated dividing true positive by summation of true positive and false positive and negative predictive value dividing true negative by summation of true negative and false negative. The accuracy of a test represents the proportion of true positive results identified by a test in the selected population. Accuracy of CRR in diagnosing neonatal sepsis was calculated as Accuracy = sensitivity) (prevalence) + (specificity) (1-Prevalence). A p-value of $<0.05$ was considered significant.

\section{RESULT}

This study included 95 neonates who met the inclusion criteria. Among them 74(77.9\%) were male and $21(22.1 \%)$ were female. $20(21.1 \%)$ were of $<37$ weeks gestation and $75(78.9 \%)$ were of $>37$ weeks gestation. Among 95 neonates $31(33.7 \%)$ were of birth weight $<2.5 \mathrm{~kg}, 59(62.1 \%)$ were of normal birth weight (2.5 $-3.9 \mathrm{Kg})$ and $4(4.2 \%)$ were of birth weight $(>3.9 \mathrm{~kg})$. Among the study population 40 (42.1\%) were delivered by SVD, 52 (54.7\%) were delivered by LSCS and 3 (3.2\%) by SVD and instrument assisted (Table1). There was no significant association of gender, birth weight, mode of delivery and gestational age of the newborn with an increase of CRP at 0 to 72 hours.

\begin{tabular}{|c|c|c|c|c|c|}
\hline \multirow{2}{*}{ Variables } & \multirow{2}{*}{ Category } & \multicolumn{2}{|c|}{$\begin{array}{c}\text { Increase CRP } 0 \\
\text { hours to } 72 \text { hours of } \\
\text { birth (n, \%) }\end{array}$} & \multirow{2}{*}{ Total } & \multirow{2}{*}{ p value } \\
\hline & & No & Yes & & \\
\hline \multirow{2}{*}{ Gender } & Male & $32(43.2)$ & $42(56.8)$ & 74 (77.9) & \multirow{2}{*}{0.722} \\
\hline & Female & $10(47.6)$ & $11(52.4)$ & 21 (22.1) & \\
\hline \multirow{2}{*}{$\begin{array}{l}\text { Gestational age } \\
\text { in weeks }\end{array}$} & $<37$ & $9(45.0)$ & $11(55.0)$ & $20(21.1)$ & \multirow{2}{*}{0.936} \\
\hline & $\geq 37$ & $33(44.0)$ & $42(56.0)$ & 75 (78.9) & \\
\hline \multirow{5}{*}{$\begin{array}{l}\text { Birth weight of } \\
\text { New born in } \mathrm{Kg}\end{array}$} & $<2.5 \mathrm{~kg}$ (LBW) & $9(39.1)$ & $14(60.9)$ & $23(24.2)$ & 0.573 \\
\hline & $\begin{array}{l}2.5 \mathrm{~kg}-3.9 \mathrm{~kg} \\
\text { (Normal) }\end{array}$ & $26(44.1)$ & 33 (55.9) & $59(62.1)$ & 0.971 \\
\hline & $<1.5 \mathrm{~kg}(\mathrm{VLBW})$ & $4(50.0)$ & $4(50.0)$ & $8(8.4)$ & 0.730 \\
\hline & $\begin{array}{l}<1 \mathrm{~kg} \\
\text { (Incredible BW) }\end{array}$ & $1(100.0)$ & $0(0.0)$ & 1 (1.1) & 0.258 \\
\hline & $\geq 3.9 \mathrm{~kg}$ & $2(50.0)$ & $2(50.0)$ & $4(4.2)$ & 0.812 \\
\hline \multirow{3}{*}{$\begin{array}{l}\text { Mode of } \\
\text { Delivery }\end{array}$} & Normal (SVD) & $19(47.5)$ & $21(52.5)$ & $40(42.1)$ & 0.582 \\
\hline & LSCS & $21(40.4)$ & $31(59.6)$ & $52(54.7)$ & 0.409 \\
\hline & $\begin{array}{l}\text { SVD and } \\
\text { instrument } \\
\text { assisted }\end{array}$ & $2(66.7)$ & $1(33.3)$ & $3(3.2)$ & 0.426 \\
\hline
\end{tabular}

Statically not significant
Similarly, Table 2 shows different reasons for which LSCS was the preferred mode of delivery among the included neonates. There was no significant difference in level of CRP titer at 0 hours to 72 hours after birth according to mode of delivery among the study population.

\begin{tabular}{|c|c|c|c|c|}
\hline \multirow[t]{2}{*}{ Reason for LSCS } & \multicolumn{2}{|c|}{$\begin{array}{l}\text { Increase CRP } 0 \text { hours } \\
\text { to } 72 \text { hours of } \\
\text { birth }(n, \%)\end{array}$} & \multirow[t]{2}{*}{ Total } & \multirow{2}{*}{$\begin{array}{l}P \\
\text { values }\end{array}$} \\
\hline & No & Yes & & \\
\hline Previous LSCS & $5(41.7)$ & $7(58.3)$ & $12(23.1)$ & 0.918 \\
\hline Failed Induction & $2(25.0)$ & $6(75.5)$ & $8(15.4)$ & 0.335 \\
\hline Failed Vacuum Extraction & $0(0.0)$ & $1(100.0)$ & $1(1.9)$ & 0.804 \\
\hline $\begin{array}{l}\text { Meconium-stained } \\
\text { Liquor }\end{array}$ & $1(25.0)$ & $3(75.0)$ & $4(7.7)$ & 0.514 \\
\hline Fetal distress & $5(38.5)$ & $8(61.5)$ & $13(25.0)$ & 0.870 \\
\hline Eclampsia & $0(0.0)$ & $1(100.0)$ & $1(1.9)$ & 0.804 \\
\hline $\begin{array}{l}\text { Cephalopelvic } \\
\text { disproportion }\end{array}$ & $2(50.0)$ & $2(50.0)$ & $4(7.7)$ & 0.683 \\
\hline Breech presentation & $1(100.0)$ & $0(0.0)$ & $1(1.9)$ & 0.777 \\
\hline severe oligohydramnios & $2(66.7)$ & $1(33.3)$ & $3(5.8)$ & 0.339 \\
\hline $\begin{array}{l}\text { Pregnancy induced } \\
\text { Hypertension (PIH) }\end{array}$ & $0(0.0)$ & $1(100.0)$ & $1(1.9)$ & 0.804 \\
\hline $\begin{array}{l}\text { Cesseration on maternal } \\
\text { request }\end{array}$ & $1(100.0)$ & $0(0.0)$ & $1(1.9)$ & 0.777 \\
\hline $\begin{array}{l}\text { Placenta previa with } \\
\text { antepartum hemorrhage }\end{array}$ & $1(100.0)$ & $0(0.0)$ & 1 (1.9) & 0.777 \\
\hline Obstetrics cholestasis & $0(0.0)$ & $1(100.0)$ & $1(1.9)$ & 0.804 \\
\hline Antepartum hemorrhage & $1(100.0)$ & $0(0.0)$ & $1(1.9)$ & 0.777 \\
\hline
\end{tabular}

Statically not significant

Table 3, shows different types of neonatal sepsis and various underlying causes for which sepsis was suspected among the study population. Out of which 84 (88.4\%) were neonates with EONS and 11(11.6\%) were neonates suspected of LONS. There was no significant association of different types of sepsis and the various underlying causes for sepsis suspicion with increment of CRP at 0 hours to 72 hours.

Among the study population 66 (69.5\%) did not have any adverse perinatal events while $29(31.5 \%)$ had some adverse perinatal events (Table 4). There was no significant association of adverse perinatal events on increment of CRP at 0 hours to 72 hours after birth. 
Table 3: Association between at 0 hours to 72 hours CRP increment with types of sepsis and other diagnosis:

\begin{tabular}{|l|c|c|c|c|}
\hline \multirow{2}{*}{\multicolumn{1}{|c|}{ Diagnosis }} & \multicolumn{2}{|c|}{$\begin{array}{l}\text { Increase CRP } 0 \text { hours to } \\
\text { 72 hours of birth (n, \%) }\end{array}$} & \multirow{2}{*}{ Total } & \multirow{2}{*}{ P values } \\
\cline { 2 - 3 } & No & Yes & \\
\hline Sepsis & & & & \\
\hline Early onset & $37(44.0)$ & $47(56.0)$ & $84(88.4)$ & \multirow{2}{*}{0.930} \\
\hline Late onset & $5(45.5)$ & $6(54.5)$ & $11(11.6)$ & \\
\hline Other risk factor for sepsis suspicion & & & & \\
\hline Birth asphyxia with prematurity with & $1(20.0)$ & $4(80.0)$ & $5(5.3)$ & 0.263 \\
\hline LBW with respiratory distress & $5(29.4)$ & $12(70.6)$ & $17(17.9)$ & 0.175 \\
\hline Congenital pneumonia & $5(41.7)$ & $7(58.3)$ & $12(12.6)$ & 0.849 \\
\hline Birth asphyxia & $3(50.0)$ & $3(50.0)$ & $6(6.3)$ & 0.768 \\
\hline Prematurity with VLBW & $8(47.1)$ & $9(52.9)$ & $17(17.9)$ & 0.794 \\
\hline Prematurity with LBW & $7(43.8)$ & $9(56.2)$ & $16(16.8)$ & 0.968 \\
\hline $\begin{array}{l}\text { Birth asphyxia with meconium } \\
\text { aspiration syndrome }\end{array}$ & & & & \\
\hline Respiratory distress & $3(50.0)$ & $3(50.0)$ & $6(6.3)$ & 0.768 \\
\hline Exaggerated neonatal jaundice & $1(25.0)$ & $3(75.0)$ & $4(4.2)$ & 0.429 \\
\hline PROM and PV leaking & $5(83.3)$ & $1(16.7)$ & $6(6.3)$ & 0.084 \\
\hline Acute Gastroenteritis & $0(0.0)$ & $1(100.0)$ & $1(1.1)$ & 0.868 \\
\hline Neonatal pustulosis & $1(100.0)$ & $0(0.0)$ & $1(1.1)$ & 0.371 \\
\hline Meningitis & $2(100.0)$ & $0(0.0)$ & $2(2.1)$ & 0.259 \\
\hline Fever & $2(100.0)$ & $0(0.0)$ & $2(2.1)$ & 0.259 \\
\hline
\end{tabular}

Table 4: Association between 0 hours to 72 hours CRP increment with adverse perinatal event and its types:

\begin{tabular}{|c|c|c|c|c|c|}
\hline \multirow{2}{*}{ Characteristics } & \multirow{2}{*}{ Category } & \multicolumn{2}{|c|}{$\begin{array}{l}\text { Increase CRP } 0 \text { hours } \\
\text { to } 72 \text { hours of birth } \\
(n, \%)\end{array}$} & \multirow{2}{*}{ Total } & \multirow{2}{*}{$\begin{array}{c}P \\
\text { values }\end{array}$} \\
\hline & & No & Yes & & \\
\hline \multirow{2}{*}{$\begin{array}{l}\text { Any adverse } \\
\text { perinatal events }\end{array}$} & No & $30(45.5)$ & $36(54.5)$ & $66(69.5)$ & \multirow[b]{2}{*}{0.713} \\
\hline & Yes & $12(41.4)$ & $17(58.6)$ & $29(30.5)$ & \\
\hline \multirow{6}{*}{$\begin{array}{l}\text { Types of any } \\
\text { adverse perinatal } \\
\text { event (for yes } \\
\text { response only) }\end{array}$} & Vehicle delivery & $1(50.0)$ & $1(50.0)$ & $2(6.9)$ & 0.691 \\
\hline & $\begin{array}{l}\text { Needed tactile } \\
\text { stimulation }\end{array}$ & $0(0.0)$ & $1(100.0)$ & $1(3.4)$ & 0.558 \\
\hline & Fetal distress & $0(0.0)$ & $1(100.0)$ & $1(3.4)$ & 0.558 \\
\hline & Instrumental delivery & $2(100.0)$ & $0(0.0)$ & $2(6.9)$ & 0.193 \\
\hline & Shoulder dystocia & $1(100.0)$ & $0(0.0)$ & $1(3.4)$ & 0.442 \\
\hline & $\begin{array}{l}\text { Perinatal Asphyxia and } \\
\text { needed extensive } \\
\text { resuscitation }\end{array}$ & $8(36.4)$ & $14(63.6)$ & $22(75.9)$ & 0.276 \\
\hline
\end{tabular}

Statically not significant

Table 5, shows different investigation parameters and their association with increment of CRP from 0 hours to 72 hours after birth. Among them 34 had positive blood culture while 61 had blood culture which was sterile. The blood culture report had significant association with 72 hours CRP increment. It showed that, $70.6 \%$ who had blood culture positive had increased CRP level at 0 to 72 hours whereas only $29.4 \%$ had not no increment in CRP despite positive blood culture. The $p$-value was $<0.05$ and was significant.
Table 5: Association between at birth to 72 hours CRP

increment and investigations:

\begin{tabular}{|c|c|c|c|c|c|}
\hline \multirow{2}{*}{ Investigations } & \multirow{2}{*}{ Category } & \multicolumn{2}{|c|}{$\begin{array}{l}\text { Increase CRP } 0 \text { hours to } 72 \\
\text { hours of birth }(n, \%)\end{array}$} & \multirow{2}{*}{ Total } & \multirow{2}{*}{$P$ values } \\
\hline & & No & Yes & & \\
\hline \multirow{2}{*}{ Blood Culture } & Negative & $32(52.5)$ & $29(47.5)$ & 61 & \multirow{2}{*}{0.030} \\
\hline & Positive & $10(29.4)$ & $24(70.6)$ & 34 & \\
\hline \multicolumn{2}{|l|}{ RBC } & -.. & $4.76 \pm 0.81$ & $4.68 \pm 0.78$ & 0.282 \\
\hline \multicolumn{2}{|l|}{ WBC } & $\begin{array}{c}16457.14 \pm \\
7018.38\end{array}$ & $\begin{array}{c}15198.11 \pm \\
5603.21\end{array}$ & $\begin{array}{c}15754.74 \pm \\
6264.81\end{array}$ & 0.333 \\
\hline \multicolumn{2}{|l|}{$\mathrm{Hb}$} & $15.98 \pm 2.22$ & $16.36 \pm 2.42$ & $16.19 \pm 2.33$ & 0.437 \\
\hline \multicolumn{2}{|l|}{ Hematocrit } & $46.86 \pm 9.25$ & $50.13 \pm 8.28$ & $48.69 \pm 8.83$ & 0.073 \\
\hline \multicolumn{2}{|l|}{ Platelet } & $\begin{array}{c}242642.86 \pm \\
97782.94\end{array}$ & $\begin{array}{c}223754.72 \pm \\
69372.99\end{array}$ & $\begin{array}{c}232105.26 \pm \\
83196.57\end{array}$ & 0.274 \\
\hline \multirow{2}{*}{ Chest X-Ray } & Normal & $34(45.9)$ & $40(54.1)$ & 74 (77.9) & \multirow{2}{*}{0.523} \\
\hline & Abnormal & $8(38.1)$ & $13(61.9)$ & $21(22.1)$ & \\
\hline
\end{tabular}

Table 6, shows that the sensitivity of CRP in the diagnosis of culture proven sepsis increased from $35 \%$ at the initial sepsis work-up to $82.22 \%$ when CRP determination was performed at 72 hours following the first one while we found specificity ranging only from 35.565 to $58.43 \%$. The positive predictive value of CRP in identifying sepsis at birth was $38.33 \%$ which was similar when calculated for CRP titer at 72 hours $38.95 \%$. The negative predictive value of CRP titer in identifying sepsis at birth was $70.27 \%$ which increased to 80.00\% when calculated for CRP at 72 hours after birth. Similarly, accuracy of the CRP titer at birth in identifying sepsis was $55.97 \%$ which calculated at 72 hours after birth was $51.11 \%$.

Table 6: Diagnostics test result CRP vs Blood culture:

\begin{tabular}{|l|c|c|c|c|}
\hline \multicolumn{1}{|c|}{ Statistic } & \multicolumn{2}{c|}{ At 0 hr. } & \multicolumn{2}{c|}{ At 72 hrs. } \\
\cline { 2 - 5 } & Value & $95 \% \mathrm{Cl}$ & Value & \multicolumn{1}{c|}{$95 \% \mathrm{Cl}$} \\
\hline Sensitivity & $51.11 \%$ & $35.77 \%$ to $66.30 \%$ & $82.22 \%$ & $67.95 \%$ to $92.00 \%$ \\
\hline Specificity & $58.43 \%$ & $47.49 \%$ to $68.79 \%$ & $35.56 \%$ & $25.74 \%$ to $46.35 \%$ \\
\hline Disease prevalence $\left({ }^{*}\right)$ & $33.58 \%$ & $25.66 \%$ to $42.25 \%$ & $33.33 \%$ & $25.46 \%$ to $41.96 \%$ \\
\hline $\begin{array}{l}\text { Positive Predictive } \\
\text { Value }\left({ }^{*}\right)\end{array}$ & $38.33 \%$ & $29.89 \%$ to $47.55 \%$ & $38.95 \%$ & $34.20 \%$ to $43.92 \%$ \\
\hline $\begin{array}{l}\text { Negative Predictive } \\
\text { Value }\left({ }^{*}\right)\end{array}$ & $70.27 \%$ & $62.57 \%$ to $76.97 \%$ & $80.00 \%$ & $66.80 \%$ to $88.83 \%$ \\
\hline Accuracy $\left({ }^{*}\right)$ & $55.97 \%$ & $47.14 \%$ to $64.53 \%$ & $51.11 \%$ & $42.37 \%$ to $59.81 \%$ \\
\hline
\end{tabular}

Table 7, shows that 72 hours CRP titer correlated better with blood culture proven sepsis in comparison to CRP titer at 0 hours after birth and $p$ value was significant. 
Table 7: CRP at 0 hours and at 72 hours after birth with blood culture

\begin{tabular}{|c|c|c|c|c|}
\hline \multirow{2}{*}{ CRP } & \multirow{2}{*}{ Test } & \multicolumn{2}{|c|}{ Blood Culture } & \multirow{2}{*}{ p value } \\
\cline { 3 - 5 } & & Negative & Positive & \\
\hline \multirow{2}{*}{ At 0 hr. } & $<6$ & 51 & 22 & \multirow{2}{*}{0.329} \\
\cline { 2 - 4 } & $\geq 6$ & 37 & 23 & \\
\hline \multirow{2}{*}{ At 72 hrs. } & $<6$ & 32 & 8 & \multirow{2}{*}{0.027} \\
\cline { 2 - 4 } & $\geq 6$ & 56 & 37 & \\
\hline \multicolumn{2}{|c|}{ Total } & 88 & 45 & \\
\hline
\end{tabular}

\section{DISCUSSION}

The signs and symptoms of neonatal sepsis can be clinically indistinguishable from various noninfectious conditions such as respiratory distress syndrome or maladaptation. Therefore, rapid diagnosis is crucial for preventing the child from an adverse outcome. Based on clinical pictures alone the diagnosis of neonatal infection is difficult to establish, yet it is crucial that treatment is instituted early because of the high mortality associated with neonatal infection. Clinical suspicion along with various laboratory sepsis markers represents a helpful tool in the evaluation of a child with clinical signs and complement the evaluation of a neonate with a potential infection. Variety of sepsis markers were studied with different success to aid diagnosis of neonatal sepsis but none of them was able to consistently diagnose $100 \%$ of infected cases. Moreover, newer markers studied are expensive to perform and not easily accessible to economically constrained countries like ours. C-reactive protein is the easily available and cheap sepsis marker useful for diagnosis of neonatal sepsis. A limited number of studies have been conducted to see whether single CRP titre or serial measurement of CRP titer at 72 hours after the first one correlates better with the blood culture. So, we aimed to study how the value of CRP titer changes at birth and at 72 hours according to demographic, laboratory and blood culture among neonatal sepsis suspected neonates at the neonatal intensive care unit of BMCTH.

In our study we also noted that there was no significant association of mode of delivery with increment of CRP at 0 hours to 72 hours after birth among the study population. Also, we noted in our study $84(88.4 \%)$ were neonates with early onset neonatal sepsis and $11(11.6 \%)$ were neonates suspected of late onset neonatal sepsis. There was no significant association of different types of sepsis and the various underlying causes for sepsis suspicion with increment of CRP at 0 hours to 72 hours after birth.

In our study, 66 (69.5\%) of the study population did not have any adverse perinatal events while $29(31.5 \%)$ had some adverse perinatal events. There was no significant association of adverse perinatal events on increment of CRP at 0 hours to 72 hours after birth. Also, we noted that none of the investigation's parameters had association with increment of CRP from 0 hours to 72 hours after birth. Among them $34(35.7 \%)$ had positive blood culture while $61(64.2 \%)$ had blood culture which was sterile. The blood culture report had significant association with 72 hours CRP increment. It showed that $24(70.6 \%)$ who had blood culture positive had increased CRP level at 72 hours whereas only10 $(29.4 \%)$ had not increased. The $p$ - value was $<0.05$ and was significant. Hisamuddin et. al in his study also has reported that the diagnostic accuracy of CRP in diagnosis of neonatal sepsis was $70.07 \%$ which is similar to finding in our study. ${ }^{4}$

In our study we also noted that the sensitivity of CRP in the diagnosis of culture proven sepsis increased from 35\% at the initial sepsis work-up to $82.22 \%$ when CRP determination was performed at 72 hours following the first one. In a similar study done by Benitz et al. found that the sensitivity in the diagnosis of culture proven early onset sepsis increased from $35 \%$ at the initial sepsis work-up to $79 \%$ and 89\% when CRP determination was performed on the two following days. ${ }^{8}$ In a large series of 689 neonates (187 with sepsis) Pourcyrous et al. reported a higher sensitivity for CRP levels determined at least 12 hours after the initial evaluation compared to the first value (54\% vs. $74 \%){ }^{9}$ In general, the sensitivity substantially increases with serial determinations 24 to 48 hours after the onset of symptoms, and several studies reported on sensitivities and specificities ranging from $78 \%$ to $98 \%$ and from $81 \%$ to $97 \%$, respectively. ${ }^{10}$ But in our study, we found specificity ranging only from 35.565 to $58.43 \%$ which was very low. So, it shows that serial CRP titers had greater sensitivities for diagnosing neonatal sepsis in comparison to single CRP titers in comparison to our study measured at 72 hours after the first. Specificity was found lesser in our studies in comparison to previous studies which may be because in previous serial CRP titers were measured earlier within 48 hours. This needs further studies measuring CRP titer earlier within 48 hours which may have greater specificity.

In our study we noted that there was no significant association of gender, birth weight, mode of delivery and gestational age with an increase of CRP at 0 to 72 hours after birth. But Ishibashi et al found that in 110 uninfected symptomatic neonates gestational age and birth weight significantly influence CRP concentration within 48 hours after birth. Neonates with low gestational age and low birth weight had lower CRP concentration. ${ }^{11}$

\section{CONCLUSION}

Level of CRP titre increment from 0 hours to 72 hours after birth did not vary with gestational age, gender, birth weight, different reasons for cesarean section, different laboratory parameters, change of antibiotics for management, adverse perinatal events and types of sepsis. Blood culture report had significant association with 72 hours CRP increment. It showed that 24(70.6\%) who had blood culture positive had increased CRP level at 72 hours whereas only10(29.4\%) had not increased.

CRP estimation does have a role in the diagnosis of neonatal sepsis but serial CRP titre increment at 72 hours of life 
correlates more with proven sepsis and has greater sensitivity in diagnosing neonatal sepsis. The test is not specific enough to be relied upon as the only indicator. The sensitivity, specificity, positive and negative predictive values as calculated in this study are not high enough to make it a good screening test. The clinical criteria along with other hematological parameters and diagnostic markers along with serial CRP should be considered in evaluating a neonate for sepsis.

\section{LIMITATION OF THE STUDY}

The study was done only for a period of 6 months duration. Still, further research is needed on the topics for longer duration of time with greater sample size to see the influence of gestational age on CRP kinetics in infection, noninfectious confounders, and the evaluation of dynamic and gestational age dependent reference values, could have better external validity.

\section{ACKNOWLEDGMENT}

I would especially like to thank Professor Dr. Hemsagar Rimal and Professor Dr. Santosh Upadhyaya Kafle for their continuous guidance and expert opinion throughout the study period.

\section{CONFLICT OF INTEREST}

\section{None}

\section{REFERENCES}

1. Hofer N, Müller W and Resch B. Non-infectious conditions and gestational age influence Creactive protein values in newborns during the first 3 days of life. Clinical Chemistry and Laboratory Medicine: CCLM / FESCC. 2011;49(2):297-302. DOI: http://dx.doi.org/ 10.5772/ 54255.

2. Murray BE. Can antibiotic resistance be controlled? The New England Journal of Medicine. 1994;330(17):1229-30.

3. Mishra UK, Jacobs SE, Doyle LW and Garland SM. Newer approaches to the diagnosis of early onset neonatal sepsis. Archives of Disease in Childhood Fetal and Neonatal Edition. 2006;91(3): F208-12-F-12.doi: 10.1136/adc.2004.064188.

4. Hisamuddin E, Hisam A, Wahid S, Raza G, et.al. Validity of C-reactive protein (CRP) for diagnosis of neonatal sepsis. Pak J Med Sci 2015;31(3):527-31.

5. Hamdoon GW, Fawzia MM and Yaseen ZM. Prognostic value of Creactive protein in neonatal sepsis. Ann Coll Med Mosul 2013; 39 (2): 136-42.

6. Minassian MA, Newnham R, Kalimeris E, Philip Bejon, Atkins BL, Bowler IC, et.al. Use of an automated blood culture system (BD BACTEC $^{\text {TM }}$ ) for diagnosis of prosthetic joint infections: easy and fast. BMC Infect Dis. 2014; 14: 233.
7. Suci Thangam G, Amuthavalli K, Velvizhi G, Ashiya Begum M.A, Jeyamurugan T, Palaniappan N, et.al. Early Diagnostic Markers for Neonatal Sepsis: Comparing Procalcitonin (PCT) and C-Reactive Protein (CRP). Journal of Clinical and Diagnostic Research. May 2012;6(4):627-31.

8. Benitz WE, Han MY, Madan A and Ramachandra P. Serial serum Creactive protein levels in the diagnosis of neonatal infection. Pediatrics. 1998;102(4): E41-E.

9. Pourcyrous M, Bada HS, Korones SB, Barrett FF, Jennings W, Lockey T, et.al. Acute phase reactants in neonatal bacterial infection. Journal of Perinatology: Official Journal of the California Perinatal Association. 1991;11(4):319-25.

10. Jaye $\mathrm{DL}$ and Waites KB. Clinical applications of C-reactive protein in pediatrics. The Pediatric Infectious Disease Journal. 1997;16(8):73546.

11. Ishibashi M, Takemura Y, Ishida H, Watanabe K, Kawai T et.al., CReactive Protein Kinetics in Newborns: Application of a HighSensitivity Analytic Method in Its Determination. Journal of Clinical Chemistry.2002; 48(7):1103-1106. DOI: https://doi.org/10.1093/ clinchem/48.7.1103. 